\title{
Artikel
}

Elisabeth Heyne*

\section{Wahrnehmungshygiene und Baumpuderrausch. Kleine amazonische Sinneslehre (Lévi-Strauss, Restany, Viveiros de Castro, Kohn, Oloixarac)}


Abstract: Der amazonische Regenwald gilt traditionell als Heimat von Sinnestäuschungen. Als das radikal Fremde hält er die selten gewordene Erfahrung bereit, sich als Mensch angesichts einer Fülle von ,Umwelt' in der Unterzahl zu fühlen. Der Beitrag untersucht vor diesem Hintergrund zwei Paradigmen amazonischer Wahrnehmungslehren. Dient er im 20. Jahrhundert als Erfahrungsort für einen letzten Rest „integraler Natürlichkeit” (Pierre Restany) und bietet eine im Verschwinden begriffene Heimat für den "chronisch heimatlosen" Europäer (Lévi-Strauss, Frans Krajcberg), scheint er dagegen im 21. Jahrhundert die dringend benötigten Wahrnehmungsmodi für die Verstrickungen zwischen Mensch, Umwelt, Tier, Pflanze und Technik im Anthropozän zu liefern (Eduardo Kohn, Eduardo Viveiros de Castro). Anhand des Romans Constelaciones oscuras (2015; dt. Kryptozän, 2016) der argentinischen Autorin Pola Oloixarac lassen sich die verschiedenen Funktionalisierungen und Imaginationen des Amazonaswaldes als Wahrnehmungsschule nachvollziehen. Zugleich ist der literarische Text mehr als nur fiktionale Verhandlung divergenter Amazonasreferenzen: Er greift indigene Perspektivverschiebungen auf, verkehrt Positiv- in Negativformen und denkt zu Ende, was aktuelle Amazonasethnographien mit Begriffen von Multinaturalismus, Schamanismus und Perspektivismus entwerfen. Da er nicht davor zurückschreckt, die letzte Konsequenz einer "anthropology beyond the human" zu ziehen, den Menschen als fremdgesteuerten Wirt einer symbiotischen Verbindung zu betrachten, lässt sich an ihm eine Wahrnehmungslehre für die Verstrickungen des Anthropozäns ableiten.

Traditionally, the Amazon rainforest appears to be the natural habitat of illusions and hallucinations. As the fundamental "other" it provides the rare experience for modern human beings to feel outnumbered when faced with the abundance of "nature", or "Umwelt". This paper examines two paradigms of amazonian perception, their theorization and literary reflection. While serving as refuge for the last remains of "integral naturalness" (Pierre Restany) or as the vanishing home for the "chronically homeless" European (Lévi-Strauss, Frans Krajcberg) in 20th century, it gives lessons on the necessary modes of perception for the 21th century and its entanglements of humans, animals, plants and technologies in the Anthropocene (Eduardo Kohn, Eduardo Viveiros de Castro). A novel by Argentinian contemporary writer Pola Oloixarac, Constelaciones oscuras (2015; engl. Dark constellations, 2019), draws attention to the different functionalizations and imaginations of Amazon forests. Moreover, the novel seizes on indigenous ontologies, reverses positive and negative forms and completes approaches of modern Amazonian anthropology and their notions of multinaturalism, shamanism and perspectivism. The text ultimately does not recoil from the idea of an "anthropology beyond the human" and its consequences: the human as an externally controlled host in a symbiotic existence. On the basis of Oloixarac's novel this paper sketches a theory of perception for the entanglements of the Anthropocene.

Keywords: Amazon, Amazonas, Wahrnehmung, Perception, Ethnologie, Anthropology and Literature, Oloixarac, Lévi-Strauss, Umwelt

*Dr. Elisabeth Heyne, Technische Universität Dresden, Institut für Germanistik, Professur für Medienwissenschaft und NdL, E-Mail: Elisabeth.Heyne@tu-dresden.de

"The Whites design their words because their thought is full of forgetting." (Davi Kopenawa zitiert nach Viveiros de Castro 2007, 154)

\section{Im Dickicht der Bäume}

In den Wäldern des Amazonasgebiets schiebt sich etwas zwischen Worte und Welten, das sich gegen die westlich geschulte Wahrnehmung sträubt: „Der Urwald ist voll von Sinnestäuschungen. Er ist voll von Träumen, Lügen, Dämonen", (Herzog 1982: TC: 43:57-44:08) brummt der alte, halbblinde Kapitän aus Werner Herzogs Fitzcarraldo, der seit längerem ohne Schiff im peruanischen Iquitos sitzt. Er habe dagegen "zu unterscheiden gelernt, zwischen der Realität und Halluzination". Für diese nicht über-, aber doch anders-sinnliche Fähig- 
keit zur Unterscheidung wird der blinde Seemann prompt vom mythomanischen Fitzcarraldo angeheuert und steuert ein Schiff heil über einen Berg, schmeckt Flusszuläufe, erspürt die Präsenz unsichtbarer Indigener. "Orinoco-Paul" legt nahe: Es bedarf einer anderen Sinneslehre, um sich im amazonischen Dickicht zurecht zu finden.

In jenem Urwald, so auch die Überzeugung der aktuellen Amazonasethnologie, "täuschen die Erscheinungen". (Viveiros de Castro 2016, 301) Und dabei ist der Dschungel des Amazonasbeckens als verheißungsvolles, lange nicht vollständig vom Westen entdecktes Anderes zugleich ein kultureller Orientierungspunkt für die Moderne. Dass der amazonische Regenwald unkartographiert oder unerschlossen scheint, ist vor allem Anlass für exzessive und dichte Beschreibung, Vermessung und Überlagerung durch Imaginationen, Fiktionalisierungen, Recherchen zur angeblichen Wildheit: Einerseits ist er der klassische Ort der Phantasmen und der Halluzinationen. Andererseits eine (Theorie-)Heimat für all jene von "chronischer Heimatlosigkeit" [déracinement chronique] (Lévi-Strauss [1955] 1981, 48) Betroffenen, die sich an der ethnologischen Auslegung des Eigenen und des Fremden versuchen. Hier lässt sich Alterität erfahren; hier ist ein Ort, der westliche Kunst- und Wissenschaftsproduktion seit den Sammelexzessen des 18. und 19. Jahrhunderts angetrieben hat. Er bietet ein $\mathrm{MaB}$ an Verfremdungsrequisiten, das erst die literarische Konturierung des Eigenen ermöglicht. Er birgt "das letzte Reservoir intakter, vollständiger (integraler) Natur" (Restany [1978] 2005, 229), das auf dem klimakatastrophischen, zerfurchten, überbevölkerten Planeten noch übrigbleibt. ${ }^{1}$ Dabei ist er als bedrohte, grüne Lunge' der Erde zugleich Sinnbild zerstörter ,Natur' und Vorzeigeobjekt des gewissenberuhigenden Klimaschutzes. Und die animistischen Vorstellungswelten seiner Bewohner*innen liefern Denkmodelle, die Auswege aus der binären Ordnung abendländischer Epistemologien versprechen.

Die Verhandlungen des Amazonas, die darauf zielen, indigene Denkweisen, Ontologien und Ökologien in ihren Einzelheiten zu verstehen und dokumentieren, sind dabei sicherlich in der

1 Den Hinweis auf Pierre Restany, der im Laufe dieses Textes noch zu Wort kommen wird, verdanke ich Marcelo Rezende, Archiv der Avantgarden, Dresden.
Unterzahl. Stattdessen ist er traditionell der Ort, an den (post-)moderne westliche Wissenschaftler*innen und Künstler*innen pilgern - und sei es nur mit dem Finger auf der Landkarte in der Pariser Bibliothèque Nationale wie Alfred Döblin -, um einen transformierten Blick aus der Fremde auf die eigene Gesellschaft werfen zu können oder um sich selbst transformiert wahrzunehmen.

Solche Lektüren des Regenwalds als GegenOrt - amazonische Lektionen in Natürlichkeit -, haben Tradition in der Moderne. Unter umgekehrten Vorzeichen bildet der Amazonas aber auch auf der zeitgenössischen Landkarte des Anthropozäns einen besonderen Fleck: Angesichts der globalen Herausforderungen und Problemlagen des, Menschenzeitalters' sind neue Wahrnehmungsweisen und Modelle für Umweltbeziehungen nötig geworden, die jenseits der Trennung von Regionalem und Globalem, von Natur, Kultur und Technologie sowie mit anderen Zeiträumen operieren. Auch das Anthropozän birgt folglich ein Wahrnehmungsproblem. ${ }^{2}$ Noch bevor eine "neue Beschreibung unserer Situation, unserer Zugehörigkeit" (Latour 2018) nötig wird, braucht es - so die Theoretiker*innen des jüngst angebrochenen Erdzeitalters - eine andere Form der Wahrnehmung dafür, wie Dinge, Tiere, Pflanzen, geologische und atmosphärische Prozesse und Menschen im Anthropozän zusammenhängen. Dieser Suche nach neuen Wahrnehmungsformen widmet sich seit längerem ein Zweig der Ethnologie, Anthropologie und Soziologie um Bruno Latour, Philippe Descola, Eduardo Viveiros de Castro, Eduardo Kohn u.a. Sie sprechen sich einerseits im Anschluss an die Science-andTechnology-Studies dafür aus, die sozialwissenschaftliche Vormachtstellung des Menschen, seine Hegemonie als sozialer Agent infrage zu stellen. Andererseits knüpfen sie an eine ethnologische Tradition an, für die Claude Lévi-Strauss als Ahne

2 Zum Beispiel beklagt bei Jane Benett: „Bilder von Odradek und die Ränder der Wahrnehmung". Renn/Scherer 2017, 47-66. In ganz anderer Hinsicht meint der Lyriker Daniel Falb, man könne das Anthropozän nicht "mit bloßem Auge" erkennen. Wird darüber gesprochen, wird zunächst einmal auf die "unsichtbaren Dinge" verwiesen, Dinge, deren (zeitliche, globale, etc.) Komplexität am besten in exponentiellen Graphen ausgedrückt werden kann: Falb 2015, 27f. Ebenso verhält es sich mit dem angenommenen Geflecht zwischen den Objekten, der Interobjektivität, unter die auch die Beziehungen von Subjekten untereinander - als Sonderfall - subsumiert werden müssten. Vgl. Morton 2013. 
dient, und versuchen von ihm ausgehend, die klassischen anthropologischen Dualismen (Natur/ Kultur, Mensch/Tier, Umwelt/Gesellschaft, Körper/ Geist) zu überwinden, ohne das strukturalistische Denken als solches zu verabschieden (Vgl. Descola 2014, 268). Alle genannten Theoretiker verbindet außerdem eine Vorliebe für eben jenen bestimmten und - verglichen mit ihren meist globalen Fragestellungen - relativ kleinen geografischen Teil der Welt.

Der Amazonas ist als Ort, an dem westliche Wahrnehmungsweisen an ihre Grenzen kommen und in ihr Gegenteil verkehrt werden, treibende Kraft für eine "Selbstauslegung im Anderen" (Rottenburg 2001, 44). Als solche ermöglicht er verfremdete Blickverschiebungen auf das Eigene. Die genannten Ethnologen gehen nun aber davon aus, dass er über seine Existenz als (Selbst-)Reflexionsfigur auch im positiven Sinne Denkmodelle bereithält, denen angesichts der wahrnehmungstheoretischen Herausforderungen des Anthropozäns neue Virulenz zukommt. Sie versuchen, Wahrnehmungsprogramme für das Anthropozän ausgerechnet an dem Ort zu finden, den man so lange als letztes Residuum von ,Natürlichkeit' konzeptualisieren konnte. Ausgangspunkte und Ziele beider Amazonaskonzeptionen - als Reservoir intakter Natur, indem sich ein Naturzustand der Sinne erlernen lasse, einerseits, und als Netzwerkmodell für die Verstrickungen des Anthropozäns andererseits - sind radikal verschieden und doch vergleichbar. Und an beiden Imaginationen und Konzeptualisierungen hat nicht zuletzt die Literatur entscheidenden Anteil, gerade dann, wenn sie konkurrierende Wissens- und Wahrnehmungsmodi zueinander in Beziehung setzt.

Die Frage nach einer amazonischen Wahrnehmungslehre wird im Folgenden mit einem Roman in Verbindung gebracht, der diese Position des Amazonas zwischen Reflexions- und positiver Wissensfigur verhandelt und zugleich mehr ist als ein literarischer Text: Die 2015 erschienenen Constelaciones oscuras (dt. Kryptozän) der argentinischen Autorin Pola Oloixarac folgen auf drei zeitlichen Ebenen von 1882 bis 2024 den fiktiven Biographien dreier exemplarischer Akteure des Anthropozäns: dem spekulativen Botaniker Niklas Bruun im 19. Jahrhundert, dem Hacker Cassio im 20. Jahrhundert und der Virologin Piera im 21. Jahrhundert. Zugleich ist der Roman die Dokumention einer "ciencia impura", der "constelaciones oscuras de la historia de la ciencia del continente del Antropoceno" (Oloixarac 2015, 144). ${ }^{3}$ Bereits sein Titel enthält verdichtet die Referenz auf ein Wahrnehmungsmodell der indigenen Völker Lateinamerikas: Die constelaciones oscuras, die "Dunklen Konstellationen", bzw. "Dunkelwolken" bezeichnen einerseits ein astronomisches Phänomen, andererseits die daraus abgeleiteten negativen Sternbilder der Inkas. Statt leuchtender Sternformationen bestehen diese aus Staubansammlungen, die durch den Kontrast mit der hell leuchtenden Milchstraße als dunkle Gebilde am Himmel erscheinen (Abb. 1), bei den Inkas trugen sie die Gestalt mythischer Tiere. Im Nachvollzug des indigenen Wissens versucht der Roman nicht das Licht, sondern die Abwesenheit von Licht wahrzunehmen, Positiv in Negativ kippen zu lassen, und zwar gerade an einem Ort, an dem „siempre hay más oscuridad que estrellas" (Oloixarac 2015, 144). ${ }^{4}$

Ausgehend von Oloixaracs Roman lässt sich ein Entwurf für eine amazonische Sinneslehre im Anthropozän skizzieren. Diese nimmt allerdings erst vor dem Hintergrund ihrer Vorgeschichte Konturen an: der Vorstellung eines Naturzustands, dem sich auch ein Naturzustand der Sinne zuordnen lässt. Zwei exemplarische Stationen dieser Vorgeschichte beleuchtet das nächste Kapitel anhand von zwei Szenen aus Wissenschaft und Kunst(kritik) im 20. Jahrhundert (II), um anschließend anhand der Constelaciones oscuras einer amazonischen Form der Wahrnehmung nachzugehen und sie mithilfe von drei Kategorien (III.1 bis 3) zu umreißen.

\section{Vom Naturzustand der Sinne}

\subsection{Heimatlosigkeit als Wahrnehmungsprogramm}

Die Tradition der Amazonasethnographie reicht weit zurück. Eines der berühmtesten frühen Beispiele sind etwa die Reisebeschreibungen von

3 Dt.: „einer ,unreinen Wissenschaft - [den] Dunkelwolken in der Wissenschaftsgeschichte des [Kontinents des, EH] Anthropozäns" Oloixarac 2016, 112.

4 Dt.: "das Ausmaß der Dunkelheit die Anzahl der Sterne um ein Vielfaches übertrifft." Oloixarac 2016, 112. 


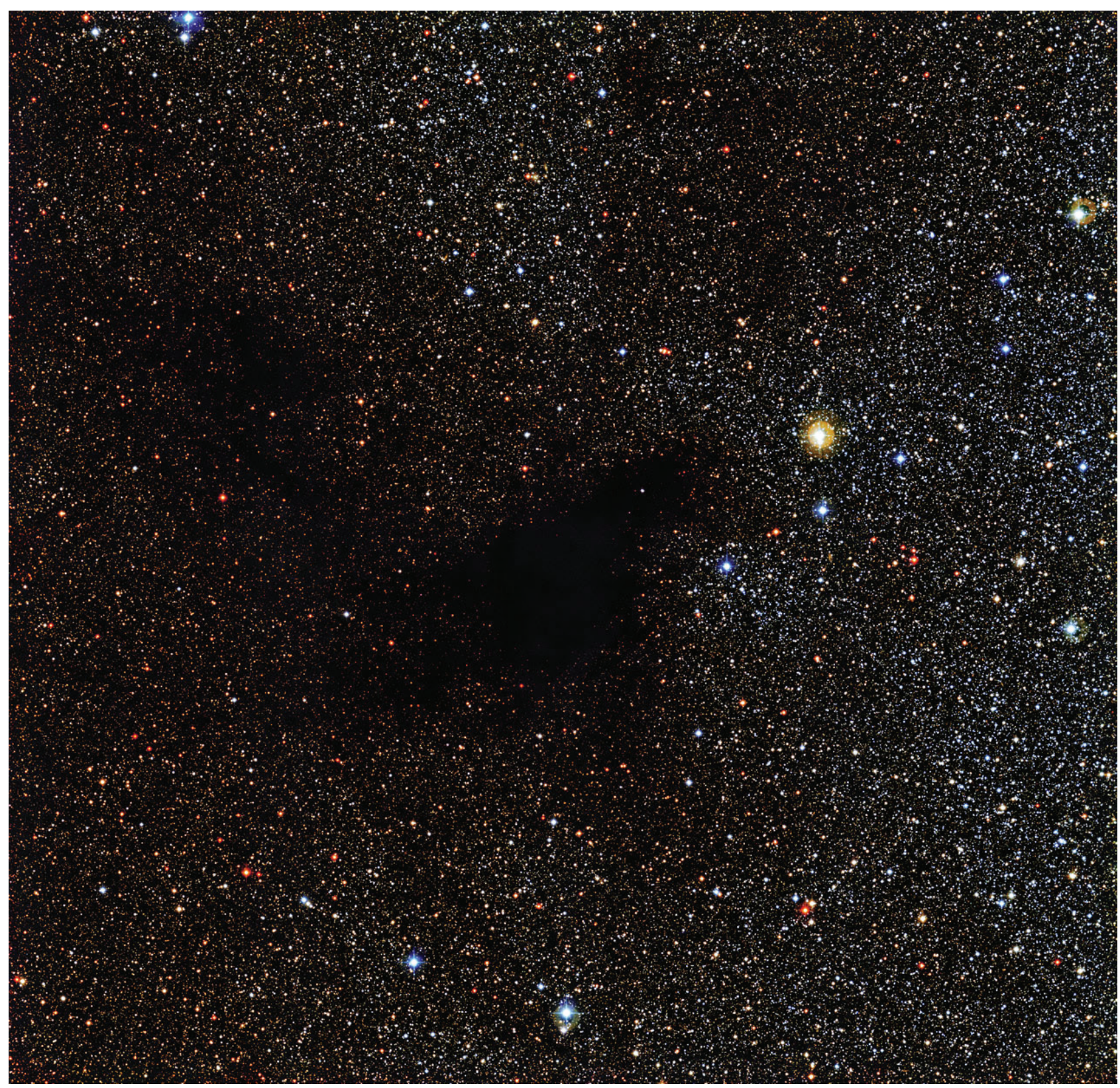

Abb. 1: Dunkelwolke

Jean de Léry aus dem 16. Jahrhundert, die wiederum Claude Lévi-Strauss in der Tasche hatte, als er sich 1935 selbst auf den Weg in den Urwald machte. Auch später ist er überzeugt, das moderne ethnographische Bewusstsein entstamme dem Amazonasgebiet (Lévi-Strauss [1955] 1981, 330). Lévi-Strauss findet eine eigene Erklärung dafür, warum es gerade der amazonische Urwald und die dort (noch) lebenden indigenen Völker sind, die schon seit Jahrhunderten das Interesse der Ethnographie erregen: Es sei das eklatante Ungleichgewicht zwischen Umwelt und Mensch, das - zumindest zum Zeitpunkt seiner
Reise - dort herrsche. Das Privileg des Amazonasgebiets sei seine relative Menschenleere. In inr bestehe seine Freiheit. Und Freiheit, so LéviStrauss, sei das „Ergebnis der objektiven Beziehung zwischen dem Individuum und dem Raum, den es einnimmt, zwischen dem Verbraucher und den Ressourcen über die er verfügt" (Lévi-Strauss [1955] 1981, 140). Lévi-Strauss folgert, dass man angesichts der Vielfalt anderer Lebensformen in den Regenwäldern des Amazonas in die Schule der ökologischen Demut gehen könne; und das heißt auch: zumindest von außen eine im Verschwinden begriffene, aber gerade noch vorhan- 
dene Welt betrachten, die der Logik des Anthropozäns Widerstand leistet.

Im Oktober 1938 reiste Lévi-Strauss durch den Regenwald, vorbei an verschiedenen Amazonaszuflüssen, auf der Suche nach einer unbekannten Gruppe von Tupi-Kawahib. In seinem melancholischen Blick auf das unter den Augen und Füßen der westlichen Mission, Kolonisation und Forschung verschwindende indigene Leben, den Traurigen Tropen, versucht er gegen den herrschenden "nostalgischen Kannibalismus" eine selbstreflexive "Archäologie der Exotik" zu setzen. Wissenschaftsbiographie, literarisierende Natur- und Abenteuerbeschreibungen und Gesellschaftsanalyse wechseln sich in seinem Text ab. Auch den amazonischen Urwald, der erst am Ende seines Buches als Akteur auftritt, beschreibt er dabei als eine Art "Gesellschaft", "[e]benso dicht, jedoch von anderen Wesen bevölkert wie unsere Städte", eine Gesellschaft, für die Lévi-Strauss noch behaupten konnte, sie habe "uns energischer ferngehalten [...] als die Wüsten, in denen wir uns so närrisch tummelten". Eine "Gemeinschaft von Bäumen und Pflanzen", aus Pilzen und Insekten, "führt darin ein unabhängiges Leben", man finde "kaum Worte, um inn [den Regenwald, EH] zu beschreiben": Er versucht es trotzdem, mit verschiedenen Vergleichen: Der Wald sei wie die Landschaften fremder Planeten, habe in Licht und Dichte eine Aquariumsatmosphäre, sei ein kompliziertes System, das statt des Auges, stärker das Gehör und den Geruchssinn anspreche, die "der Seele näherstehenden" (Lévi-Strauss [1955] 1981, 337) Sinne.

Da, wo die Beschreibungssprache des Feldforschers ganz offensichtlich an ihre Grenzen kommt, sucht er nach einer Neuausrichtung seiner Sinne: Angesichts der Dichte des amazonischen Waldes, die die westliche Wahrnehmung heraus- und überfordere, gerate das Primat des Auges an seine Grenzen. Stattdessen tritt im Text plötzlich eine Akteurin auf den Plan, die bis dahin unerwähnt geblieben war und auch später nicht mehr vorkommen wird: Lucinda. Lucinda ist ein Affenweibchen, das Lévi-Strauss als Junges von einer Nambikwara-Frau erhält, die Lucinda bis dahin aufgepäppelt hat (Abb. 2).

Abends flößt er dem Tier, das inn seitdem begleitet, Whiskey ein, um etwas Ruhe vor ihm zu haben, denn Lucinda hat sich einen seiner Stiefel ausgesucht, als "einzigen Ort der Sicher- heit in diesem Wald, in dem sie zwar auf die Welt gekommen war, den ihr die wenigen in der Nähe des Menschen verbrachten Monate jedoch so entfremdet hatten, als sei sie in der raffiniertesten Zivilisation großgeworden" (Lévi-Strauss [1955] 1981, 338). An diesem Stiefel hält sich das vom Wald entfremdete Tier bei den täglichen Märschen durch den Wald fest und ist nicht dazu zu bewegen, stattdessen etwa auf seinem Arm Platz zu nehmen. Diese zusätzliche Schwierigkeit führt nun dazu, dass der ohnehin beschwerliche Weg durch "das schwankende Geflecht" (Lévi-Strauss [1955] 1981, 338) von den klagenden Schreien Lucindas begleitet wird, wenn Dornen, Zweige und Schlammlöcher sie bedrohen. So hinkt der Ethnologe unter lautem Gezeter des Affens seinem Vordermann hinterher, bis sich die deutliche Komik der Situation und die Müdigkeit des Marschierenden schließlich in drei Vierzeiler ergießt, die nicht Lévi-Strauss, wie der Text suggeriert, sondern vielmehr die Aquariumsatmosphäre selbst hervorbringt.

Dans la forêt céphalopode / gros coquillage chevelu / de vase, sur des rochers roses qu'érode/ le ventre des poissons-lune d'Honolulu. (Übers. EH)

Im Kopffüßer-Wald / große zottelige Muschel / von Schlamm, über den rosigen Felsen erodiert / der Leib von Mondfischen aus Honolulu.

Vor seinem Kurzgedicht nutzt Lévi-Strauss zunächst seine tierische Begleiterin Lucinda dafür, einen Ausweg aus seiner Wahrnehmungsüberforderung zu finden. Sie taucht hier, an der Stelle, an der die Beschwerlichkeit der Reise, das fremdartige und geschlossene Universum des Waldes sowie die deutliche Asymmetrie zwischen Mensch und Umwelt so eklatant erscheinen, als Spiegelfigur auf. Mit ihr lässt sich die beschwerliche Passage des Zivilisierten durch die submarine, exotische und zersetzende Dichte, die radikale Fremderfahrung erst eigentlich erfassen. Auch sie ist, obgleich qua Geburt Teil der amazonischen Ökologie, ausgeschlossen und gerade dadurch der Verantwortung des Menschen anheimgegeben, der erst über sie als künstlich hergestellter Figur der Entwurzelung die Gefahren und Beschwerlichkeiten, die eigentlich besonders inn selbst betreffen, zu erkennen vermag. Lévi-Strauss' demütige Erfahrung gipfelt folglich nicht in der Kontemplation des Unterwasserwaldes, der ihm fremd, unverständ- 
lich und über Lucinda vermittelt feindlich bleibt, sondern - am deutlichsten hörbar im Schrei des Affen - in einem ethischen Diskurs: "für uns Europäer und Landbewohner, bedeutet das Abenteuer im Herzen der Neuen Welt zunächst, daß diese Welt nicht die unsrige war und daß wir die Verantwortung für das Verbrechen tragen, sie zu zerstören; und zuletzt, daß es keine andere mehr geben wird" (Lévi-Strauss [1955] 1981, 389).

Die amazonischen menschlichen Gesellschaften gehören durch ihre minoritäre Position im Kontext all der "Umwelt", die sie umgibt, anders strukturierten ökologischen Ordnungen an als ihre westlichen Beobachter*innen. Traditionell zeugt allein die hohe Sterblichkeitsrate der frühen Amazonasreisenden von der Ohnmacht des westlichen Menschen, sich in diese Form der amazonischen Umwelt einzupassen (Hermannstädter 2002). Für Lévi-Strauss liegt in dieser Unterlegenheitserfahrung nun epistemologisches Potenzial. Von ihr aus lasse sich eine neue Perspektive auf die eigene Gesellschaft gewinnen, zugleich könne man sich so von ihr "emanzipieren" (Lévi-Strauss [1955] 1981, 388). Denn Ethnolog*innen leiden, das ist sein Ausgangspunkt, an "chronischer Heimatlosigkeit". Um überhaupt Ethnolog*in zu werden, muss man seine eigene kulturelle Zugehörigkeit aufgeben, ein „Entwurzelter" [déraciné] wie Lucinda werden, um ganz in die Fremde einzutauchen. Damit verbaue man sich bewusst die Möglichkeit, in die Selbstverständlichkeit der "Verwurzelung" zurückzukehren, gewinne aber die Möglichkeit, andere "Heimaten" zu erkunden und damit wiederum Perspektiven auf seine Herkunftsgesellschaft zu gewinnen. Die Heimatlosigkeit wird also zur wahrnehmungstechnischen Grundvoraussetzung der Ethnologie.

Im Falle der amazonischen Dichte droht nun der heimatlose Blick zu scheitern, weil statt optischer Wahrnehmung andere Sinne nötig sind - solche, die der "Seele näherstehen". Die erforderliche Wahrnehmungsleistung wird in der Logik des Textes von einem Tier erbracht, das selbst zunächst Entwurzelung erfahren musste, also die Erfahrung des Ethnologen umkehrt und zugleich doppelt. Lévi-Strauss' anthropomorphisierende Zuschreibungen legen also nahe, dass die der Seele näherstehenden Sinne den Bereich einer tierischen, ,natürlichen' Wahrnehmung bezeichnen, mit der sich durch die zum Menschen analoge Heimatlosigkeit ein Blick zurück auf ihre, natürliche Heimat' werfen lässt. Ist im Folgenden also von natürlicher Wahrnehmung die Rede, so zielt dies nicht auf Naturwahrnehmung, um Gefühle der Erhabenheit, der Erholung oder der Ganzheitlichkeit hervorzubringen. Es geht um die Konstruktion eines Naturzustands der Sinne angesichts der Dichte des Amazonas, die bei Lévi-Strauss (und anderen) als solche gesetzt wird, und schließlich der poetischen und künstlerischen Sprache - oft unter Verwendung tierischer Vermittlungsinstanzen - näherzustehen zu scheint als der wissenschaftlichen Reflexion.

\subsection{Wahrnehmungshygiene}

Zur selben Zeit als Lévi-Strauss 1955, vor dem Hintergrund des Holocausts und Hiroshima, seinen Abgesang auf die Tropen verfasst, verlässt 1948 ein Künstler Europa in Richtung Brasilien, der als einziger seiner Familie die Shoa überlebte. Der in Polen geborene Künstler Frans Krajcberg, der als entscheidender Vertreter der Eco Art berühmt werden sollte, errichtet, in Brasilien angekommen, ein Haus mitten im Paraná-Wald. Dank der Immersion in die vegetabile Welt fühle er sich erstmals "chez soi" (Mollard/Lismonde 2005, 113). ${ }^{5}$ In den 1950er Jahren intensiviert sich die brasilianische Landwirtschaft, Wälder werden zugunsten von Kaffeeplantagen vernichtet, und Kracjbergs Haus fällt einer Brandrodung zum Opfer. Die Erinnerung an brennende Menschenberge in den Krematorien der Konzentrationslager wiederholt sich in seinen Augen angesichts der brennenden Bäumen des amazonischen Regenwaldes in einer "Shoa de la nature" (Mollard/Lismonde 2005, 152). ${ }^{6}$

In seinem zweiten, nun von der Regierung Brasiliens unterstützten Siedlungsversuch errichtet er auf einem monumentalen abgestorbenen Stamm ein Baumhaus nahe des amazonischen Waldes, in dem Leben, Kunstwerk und Natur zusammenfallen sollen, ein Ausdruck der "arborescence originelle du monde" (Mollard/Lismonde 2005, 114).

5 "Ici, à Nova Vicosa, dans ma forêt profonde, sur ma branche indestructible, je me sentais enfin protégé!" Mollard/Lismonde 2005, 113.

6 „Et chaque fois que je vois l'entassement des arbres d'Amazonie brûlés par les hommes, je ne peux m'empêcher de penser à la cendre des fours crématoires: les cendres de la vie, les cendres des homme devenues fous." Mollard/Lismonde, S. 64. 


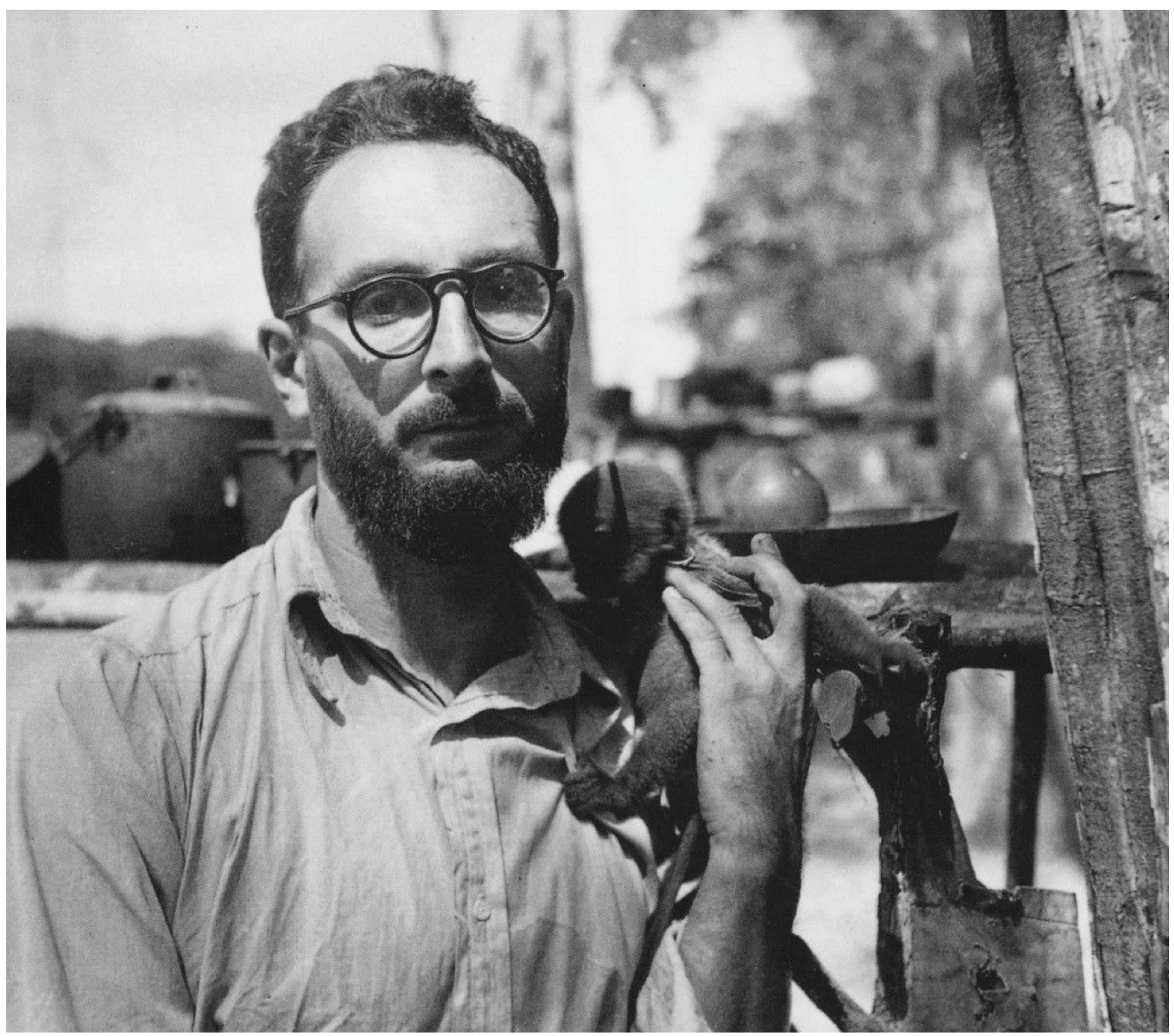

Abb. 2 Claude Lévi-Strauss und Lucinda

Seine erste Reise ins Amazonasgebiet 1966 konfrontiert ihn mit der systematischen Auslöschung des Waldes wie des indigenen Lebens. Sein politisches Engagement gegen die industrielle Zerstörung des Waldes und den Mord an seinen Bewohner*innen spannt sich von dokumentarischer Fotografie bis zu hybriden Kunstwerken aus verbranntem Holz, in dem die Natur als Zeugin ihrer eigenen Vernichtung auftreten soll. Ähnlich wie Lévi-Strauss versucht sich Krajcberg nicht an einer direkten Auseinandersetzung mit dem europäischen Holocaust, sondern überträgt seine ethische Perspektive von Menschen auf Bäume. In Form einer Perspektivverschie- bung wird hier zunächst die amazonische Dichte zur Verhandlung europäischer Gewaltgeschichte genutzt, bevor der Ansatz sich als gezielter Klimaaktivismus verselbstständigt.

Als Krajcberg in den 1970er Jahren den französischen Kunstkritiker Pierre Restany einlädt, um mit inm Brasilien zu bereisen, wird die Reise für Restany zum Initiationsmoment für ein neues Kunstverständnis, das der "Natur" Vorrang einräumen solle. Während für Krajcberg die menschliche Existenz grundsätzlich zu potenzieller Naturzerstörung führen müsse, meint Restany in Krajcbergs Kunst eine "direkte Sprache", einen authentischen 
Ausdruck des amazonischen Waldes, zu erkennen. ${ }^{7}$ Diese Vorstellung verdichtet Restany noch auf dem Schiff, mit dem er an der Seite von Krajcberg den Rio Negro entlang steuert, zu seinem Manifest für den integralen Naturalismus. In den Ökoskulpturen des polnischen Künstlers gehe es um das "Auslösen von Wahrnehmungsoperationen", die Natur und Mensch zusammenfinden ließen (Mollard/Lismonde 2005, 130). Denn die Liebe zur Natur bestehe, so Restanys Manifest, in einer "discipline de la perception, une hygiène ou une gymnastique de la sensibilité, dont la finalité tendrait à une plus exacte mesure des rapports humains, à une compréhension plus spontanée des bases de la communication et du langage." ${ }^{18}$ Das Komplement dieser neuen Form von Wahrnehmung sei eine "ésthétique géneralisé", eine verallgemeinerte Ästhetik: "Si tout art est dans la nature, il faut apprendre à voir. [...] Apprendre à voir, c'est avant tout se méfier des facilités et des complaisances de l'œil." "9 Diese Form des Sehens spiele sich nicht im Auge ab. Es sei vielmehr eine Arbeit gegen das Auge, mit dem der Realismus - verstanden als machtvoller Blick, der sich interventionistisch gegenüber seinem Objekt verhalte - von einem "integralen Naturalismus" ersetzt werden müsse: indem die Natur die Wahrnehmung prägt, und nicht andersherum.

Während Krajcberg vor allem Zerstörung wahrnimmt, setzt Restany, auch wenn mit ihm die Bedrohung des Waldes mit einem Blick auf die europäische Kolonisierung verbunden ist, in seinem Manifest von 1978 anders an und erkennt im Amazonas „aujourd'hui sur notre planète l'ultime réservoir, refuge de la nature intégrale"10 Für Krajcberg ist die im Manifest verkündete Kultur der Natur immer auch politisch gegen die Ausbeutung des Planeten und gegen die Kolonisie-

7 Pierre Restany: „la poésie vierge d'un langage direct”, zitiert nach Mollard/Lismonde 2005, 128.

8 Pierre Restany, zitiert nach Mollard/Lismonde 2005, 130. "Disziplin der Wahrnehmung, einer Hygiene oder Gymnastik der Sensibilität [sensibilité], deren Zweck auf eine exakteres Maß der menschlichen Beziehungen abzielt, auf ein spontanes Verständnis der Grundlagen von Kommunikation und Sprache." [Übers. EH]

9 Mollard/Lismonde 2005, 131. "Wenn alle Kunst in der Natur ist, dann muss man sehen lernen. [...] Sehen lernen, das heißt zunächst einmal, den Einfachheiten und den Selbstgefälligkeiten des Auges zu misstrauen" [Übers. EH]. 10 Restany 2005 [1978], 229. „Der Amazonas bildet heute auf unserem Planeten das letzte Reservoir, Refugium intakter, vollständiger (integraler) Natur." [Übers. EH] rung gewendet, obwohl kritische Stimmen in dem Manifest gerade einen kolonialistischen Ansatz erkannten. ${ }^{11}$ Restanys Wahrnehmunghygiene zielt auf etwas anderes: Seinen Amazonasschock, den er als kurzzeitig "Entwurzelter" auf dem Rio Negro erfährt, kann zwar nicht ausblenden, dass die Natur, die inm hier entgegenschlägt, radikal bedroht wird, und doch konstruiert er sie als unberührtes Gegenüber. Er fällt zurück in einen naiven Gegensatz von kultureller Intervention und natürlicher Vollständigkeit. Dieser müsse sich die menschliche Wahrnehmung unterordnen lernen. Erneut taucht hier die Idee einer demütigen Lektion in amazonischer Natürlichkeit auf, der sich schon Lévi-Strauss unterziehen wollte. Angesichts der amazonischen Dichte scheine es, so Restanys Manifest, einen Naturzustand der Sinne zu geben, den der westliche Wahrnehmungsapparat (wieder) erlernen könne. Kurz vor ihrem Verschwinden verspricht hier die radikal fremd konstruierte Natur einen letzten Ausweg und wird noch in den 1970er Jahren zum Garant von Reinheit, die sich durch sinnliche Wahrnehmung, wenn sie nur hygienisch genug verfährt, erreichen lasse.

\section{Constelaciones oscuras: Multinaturalismus als Wahrnehmungsmodell}

Die argentinische Gegenwartsautorin Pola Oloixarac, fasziniert von Fitzcarraldo-Figuren, ${ }^{12}$ betrachtet in ihren Constelaciones oscuras verschiedene

11 Zurück aus dem Urwald geben sie eine Pressekonferenz in São Paulo, um die Eckpfeiler des „integralen Naturalismus" zu skizzieren. Anlässlich dessen kommt es zu GegenDemonstrationen: Die Gringos wollten Brasilien und seine Kunst dominieren. Wer hat das Recht, für den Amazonas zu sprechen? Schreibt sich hier die Kolonisierung in Gestalt des westlichen Blicks nur weiter? Auch in Europa gibt es Gegenwind, starke Polemiken gegen die Aufwertung der "Natürlichen Schönheit": Die Ausrufung der „Kultur der Natur" sei reaktionär - stattdessen wolle man eine Opposition von Natur und Kultur. - Sie seien ihrer Zeit voraus, meint Krajcberg. Vgl. Mollard/Lismonde 2005, 138.

12 Wie ihr Opernlibretto über die Amazonasreise von Hércule Florence, einem französisch-brasilianischen Fotografen und dem deutschen Naturforscher Georg Heinrich von Langsdorff im 19. Jahrhundert beweist: Vgl. Pola Oloixarac: Hércules en el Mato Grosso, uraufgeführt 2014 im 
Akteure in ihren amazonischen Verstrickungen. Ihr Roman agiert jenseits der Vorstellungen von ethnographischer Heimatlosigkeit und tropischer Wahrnehmungshygiene und zeigt zugleich, was sich aus der Überwindung beider Paradigmen gewinnen lässt. Die erste der drei Erzählebenen setzt im Jahr 1882 ein, dem Todesjahr Darwins, und folgt dem europäischen Botaniker und Anthropologen Niklas Bruun u.a. in den brasilianischen Urwald, wo er in einer Zeit verschiedener "Theorien der Weltbeschreibung im Widerstreit" (Oloixarac 2016, 16; 2015, 24f.) die Hybriden und Transformationen zwischen Mensch, Tier und Pflanze studiert, die sich nicht mit einem evolutionären Denken im Sinne Darwins vereinbaren lassen. ${ }^{13}$ Die zweite Ebene des Romans überträgt diese Neigung zu den Hybriden ins 21. Jahrhundert und auf die Verbindung genetischer und digitaler Codes. Sie erzählt von Kindheit und Jugend des argentinisch-brasilianischen Hackers und Ethnologinnensohns Cassio Liberman Brandão da Silva in Buenos Aires, geboren 1983, zum Ende der Militärdiktatur in Argentinien. Dieser leakt schließlich 2024, auf der dritten Zeitebene, gemeinsam mit der Biologin Piera eine auf internationale Überwachung zielende Gendatenbank, indem er in seinen eigenen Körper einen von ihr entwickelten digital-genetischen Virus injizieren lässt. Alle drei verbindet ein wissenschaftliches Projekt: den westlichen Binarismus, die herrschenden Taxonomien, Ordnungen und totalen Vermessungen sowie die Grenzen des Menschen zu sprengen, alle drei nehmen Ausgang - oder suchen ihn - in den Wäldern.

Als lateinamerikanische Autorin betont Oloixarac in ihrer paratextuellen Inszenierung immer wieder ihre Zwischenposition zwischen westlich geprägter Perspektive und peruanischer, angeblich tropennaher Herkunft, mit deren Außenwahrnehmung sie in Interviews, Tweets und Kommentaren spielt. Ihr Roman ist Literatur des Anthropozäns, weil er Technologie, Popkultur und Naturgeschichte, Ethnographie, (Internet-) Geschichte und dystopische Zukunftsvision miteinander verschränkt. Er ist zugleich ein Text über

Teatro Colón, Buenos Aires. Der Urwald, davon geht sie zudem zusammen mit Fitzcarraldo aus, sei die beste Oper. 13 Als zweiter Todesstoß für Darwin sozusagen, der sich in seinen letzten Arbeiten ebenfalls vor allem der Botanik zugewandt hatte. das Anthropozän. Dessen Beginn setzt die Erzählstimme vage auf 1945 - und verknüpft seine Geschichte mit Argentinien und den Verstrickungen zwischen Wissenschaft, Politik, dem Bündnis mit Nazi-Deutschland, dessen Wissenschaftler*innen und technologischen Investitionen. Der amazonische Urwald, ${ }^{14}$ der für den Roman mehr als nur Schauplatz und Requisite ist, trägt die gleichen Wahrnehmungsprobleme in den Roman hinein, denen bereits Lévi-Strauss, Restany oder "Orinoco-Paul" begegneten: Die schier unfassbare Dichte des Waldes; die Überzahl nichtmenschlicher Akteure und die Verkehrung des Verhältnisses zwischen Mensch und Umwelt; Mischwesen zwischen Mensch, Tier und Pflanze und schließlich die Frage: Was ist Halluzination, Täuschung, Rausch, und was ist Realität im Amazonas? Aus diesen drei Punkten (Dichte/Hybride, Perspektivverschiebungen, Rausch) ergibt sich ein Gegenvorschlag, den der Roman gegen die Idee einer Wahrnehmungshygiene entwirft. Er wendet diese in ihr Gegenteil, um mit dem apokalyptischen Stoff des Anthropozäns, "la trama apocalíptica del Antropoceno" (Oloixarac 2015, 25), sowohl die Gegenüberstellung von aktiv-übergriffigem Menschlichem und "integraler" Natur als auch einen Naturzustand der Sinne zu verabschieden und durch eine ethnographische Perspektive stattdessen auf die Prothetik von Wahrnehmung zu setzen. Den Roman an diesen Punkten mit aktuellen Überlegungen aus der Amazonasethnologie zu kontrastieren hilft zu erkennen, wie er deren Erkenntnisse reflexiv aufnimmt und sowohl vergleichend in die Vergangenheit als auch dystopisch in die Zukunft verlängert.

\subsection{Dichte: Hybride und Ähnlichkeiten}

Fast jede Beschreibung des Amazonaswaldes merkt als erstes dessen Dichte an. Es ist nicht die Dunkelheit deutscher Waldeinsamkeit, sondern es ist die erdrückende, leuchtende Dichte eines Artenreichtums, den die Betrachtenden nicht zu

14 Der Roman parallelisiert über den Aspekt der Dichte den amazonischen Urwald, in dem Cassios Mutter als Ethnologin forschte, mit dem Internet, dem netzwerkförmigen, übervollen und scheinbar undurchdringlichen Urwald Cassios. 
fassen vermögen, der Ursache und Ausdruck der Heimatlosigkeit des Fremden inmitten einer überbordenden Fülle an „Natur" scheint. Der Botaniker Niklas Bruun, fiktiver Autor von De flora subterranea, eines wissenschaftlichen Werks von halluzinierender Prosa, das das Komplott und die Erzählfetzen des Anthropozäns vorausahnen sollte, begegnet dieser Dichte Ende des 19. Jahrhunderts auf andere Art und Weise (Vgl. Oloixarac 2015, 24, 137; Oloixarac 2016, 16, 106).

Beeinflusst von einem Anhänger der "botánica especulativa" (Oloixarac 2015, 142; Oloixarac 2016, 110), einem spekulativen Botaniker, in dessen brasilianischen Refugium nahe des Amazonas Niklas schließlich strandet, begibt er sich mit diesem flussaufwärts in das Innere des Amazonasgebiets, auf der Suche nach einem nichtmenschlichen Wesen, das mitten im Urwald ein botanisch-hybrides Laboratorium unterhalte (Abb. 3). Wenn der Text nahelegt, es war, als würden sie dabei "volver a los inicios de la creación" (Oloixarac 2015, 208), ${ }^{15}$ dann ist damit nur bedingt eine ganzheitliche göttliche Schöpfung gemeint, sondern eine hybride Kreatur, "una rata de unos seis pies, perfectamente adiestrada en el arte del habla humana, que ejercía con sorna" (Oloixarac 2015, 214). ${ }^{16}$ Hoichi, so der Name dieser Schöpfung, züchtet mitten im Amazonasurwald eine halluzinogene Pflanze, Crissia pallida, in den Körpern von Frauen, die er zuvor in einen künstlichen Schlaf versetzt. Sein eigentliches Ziel ist es, die Menschheit in im Dunkeln hausende Wurmwesen zu transformieren. Von seinem amazonischen Laboratorium aus solle die Neue Welt in einem post- bzw. antikolonialen Feldzug die Alte verschlingen.

Hoichis Laboratorium, in dem sich Niklas plötzlich wiederfindet, ohne genau zu wissen, wie er hineingelangt sein könnte, verströmt den "[o] Ior a rancio, a biblioteca encerrada en el medio de la selva" (Oloixarac 2015, 210). ${ }^{17}$ Es ist ein verfallenes Gebäude, das längst von der Ordnung des Vegetabilen zurückerobert wurde. Solche

15 Dt.: „Es war, als ob sie zu den Ursprüngen der Schöpfung zurückkehrten.", Oloixarac 2016, 165.

16 Dt. : „eine sechseinhalb Fuß große Ratte, die die menschliche Sprache perfekt beherrschte, eine Kunst, die sie mit sarkastischem Unterton ausübte", Oloixarac 2016, 169.

17 Dt. : „Ein ranziger Geruch lag in der Luft, als hätte man sie mitten im Urwald in eine alte Bibliothek eingeschlossen.", Oloixarac 2016, 166. in Pflanzen verwandelte Gebäude bilden häufig den Hintergrund für Niklas' Reisen. Keine unberührte Natur, sondern Räume, die sich in ständiger Transformation befinden. Die Dichte, mit der Niklas hier konfrontiert ist, folgt also einer anderen Ordnung: Es ist die Dichte, die dann entsteht, wenn die Botanik nicht mehr Arten beschreibt, sondern erfindet, die Dichte eines Netzes, in dem die Natur nicht mehr das passive, schutzsuchende Opfer menschlicher, expansiver Aktion ist, sondern sich an ihre Stelle Hybride zwischen Humanem, Tierischen und Floralem sowie zwischen genetischem und digitalem Code schiebt.

Die Dichte, die Niklas hier eher riecht als sieht, bewegt sich jenseits der Kategorien des Räumlichen:

Entonces Niklas, según su diario, empezó a dibujar y a describir todo lo que veía. Sólo que lo que veía no tenía formas espaciales, parecía del orden de pensamientos que recubrían las cosas, como si describiera el manto de terciopelo que sin embargo delinea cuidadosamente lo que cubre y protege. (Oloixarac 2015, 213) (8 $^{18}$

Die Beschreibungssprache, die er schließlich für das Formlose findet, ist wie ein "Mantel, der das, was er bedeckt und schützt, gleichzeitig auch sanft konturiert". Die Wahrnehmung des Formlosen eröffnet eine alternative Ordnung (III.2) und betont die verhüllende und formende Funktion von Sprache, die im Kontext eines Hygienedispositivs scheitern muss. Die Formlosigkeit ist also eigentlich nur der Effekt einer inadäquaten Sprache: In der post- und antidarwinistischen genetischen Geschichte der Vermischungen und Einschreibungen, der sich der Roman widmet, befinden sich die Formen grundsätzlich im Wandel, ohne dass dies für den Menschen wahrnehmbar wäre. Im Amazonas wurde nicht nur die Mimikry entdeckt, ${ }^{19}$ dort verdichten sich für Niklas auch die Hinweise auf eine alternative Taxonomie, die nicht auf Abstammung, sondern

18 Dt.: „Seinem Tagebuch zufolge zeichnete und beschrieb Niklas ab diesem Moment alles, was er hörte und sah. Doch das, was er sah, besaß keine räumliche Form, vielmehr schien es einer gedanklichen Ordnung anzugehören, die sich über die Dinge legt. Es war, als beschriebe er den samtenen Mantel, der das, was er bedeckt und schützt, gleichzeitig auch sanft konturiert." Oloixarac 2016, 169.

19 Siehe zu den täuschenden Ähnlichkeiten in der Fauna der "Neuen Welt" Heyne 2019 sowie ausführlicher Heyne 2020, 166-182. 


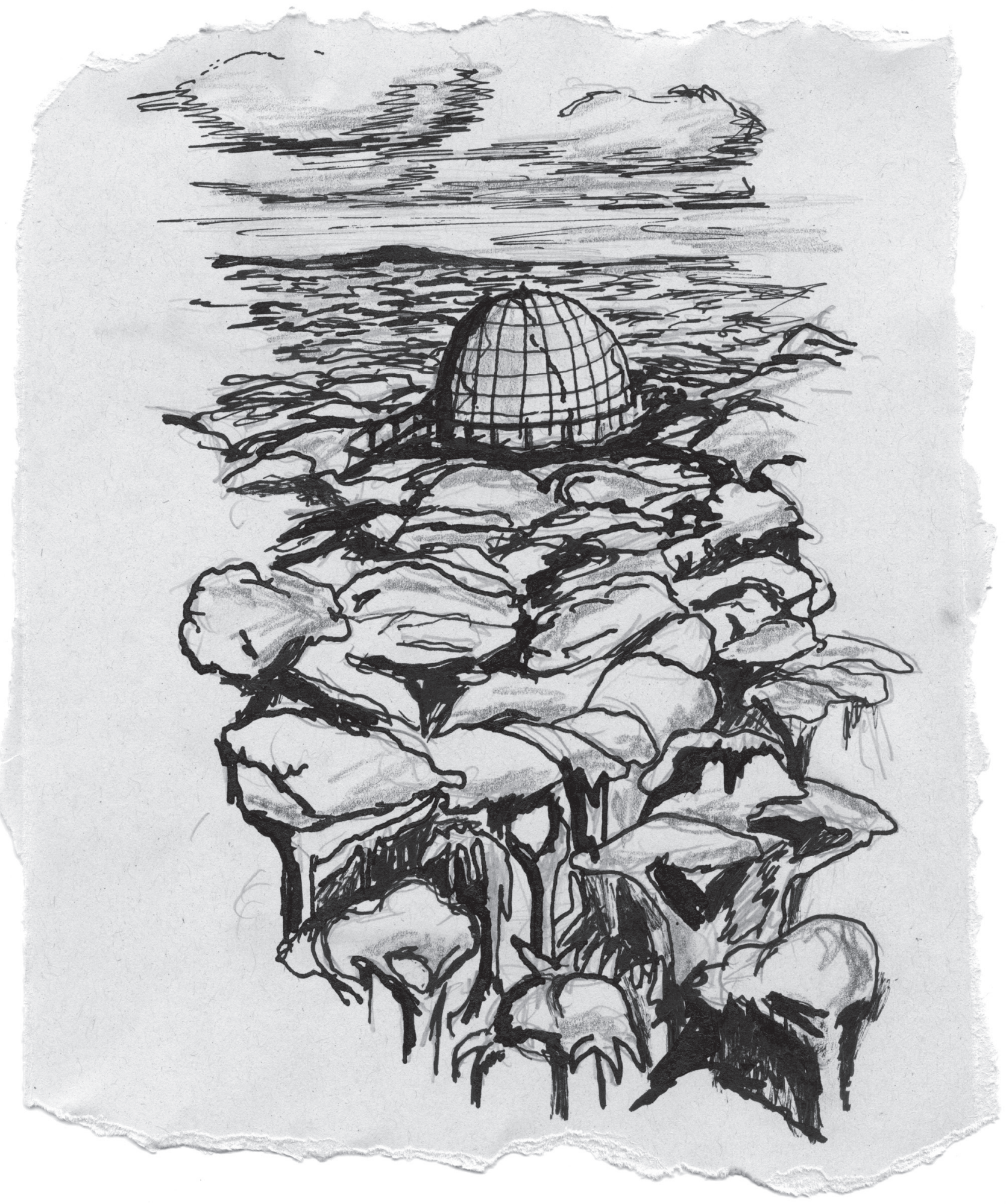

Abb. 3: Das botanisch-hybride Laboratorium inmitten des Urwalds, Abbildung in der deutschen Übersetzung (Jonathan Guggenberger)

auf deutlich rasanter ablaufenden mimetischen Prozessen und feindlichen Übernahmen einer Art durch die andere basiert, auf eine alternative Evolution, quer zu den Grenzen der Arten, als
"Symbiosen und Tauschgeschäfte". Diese mimetische, antidarwinistische Theorie zum Artenwandel hatte der Text zuvor mit einem Hinweis auf die einst im Amazonasgebiet angesiedelten

K ) W 
Tupinambá bereits auf der zweiten Erzählebene um den Hacker Cassio eingeführt: „En la mitología tupinambá, los encuentros entre especies diferentes son sucesos del orden maravilloso. Una especie comienza por imitar a otra, empieza por poseer sus gestos para después comérsela" (Oloixarac 2015, 36). ${ }^{20}$ Mimikry ist hier also nicht Schutz oder Drohgebärde, sondern funktioniert nach Art eines trojanischen Pferds. Zugleich ist sie eine soziale Kategorie (Oloixarac 2015, 37; 2016, 28): ${ }^{21}$ Evolution wartet nicht die Zyklen des Generationswechsels ab, sondern vollzieht sich, so Niklas Entdeckungen, im Individuum über Begegnungen und Kontrakte und erzeugt alternative Formen der Verwicklung und Verdichtung. ${ }^{22}$ Andererseits durchzieht den Roman die Ahnung, dass sich Umwälzungen in so großen zeitlichen Dimensionen vollziehen, dass sie für den Menschen unsichtbar bleiben; dass also ganze Ordnungen und Verknüpfungen für den Menschen jenseits des Wahrnehmbaren liegen. Im Kontext des wissensarchäologischen Zugriffs des Romans wird diese alternative Form der Artentwicklung, die quer zu den Grenzen des Menschlichen verläuft, zu einem gleichberechtigten Teil der unterirdischen konkurrierenden Narrative des Anthropozäns.

Die Suche nach einem "letzten", durch die expansive menschliche Nutzung und Manipulation von Umwelt gefährdeten, also schließlich auch vom Menschen schützenswerten Refugium

20 Dt.: „In der Mythologie der Tupinambá gelten Begegnungen zwischen unterschiedlichen Arten als feste Bestandteile eines göttlichen Plans. Eine Art imitiert zunächst die andere, eignet sich ihre Gesten an, um sie anschlieBend zu fressen." Oloixarac 2016, 27.

21 Parallel taucht in Cassios Jugendlektüren immer wieder die Mutantenratte Splinter aus der Ninja-Turtles-Comicserie der 1980er Jahre auf, die durch Nachahmung die Gesten ihres Herrchens erlernt hatte und so unter Menschen lebte, vgl. Oloixarac 2015, 59; Oloixarac 2016, 44.

22 Vgl. Oloixarac 2015, 140: "Los cambios eran mucho más rápidos: ocurrían durante la vida misma del individuo, se daban por contactos inesperados y por mímesis que no esperaban el trabajo silente de ciclos reproductivos que se seleccionan los mejores rasgos." Oloixarac 2016, 109: „Die Veränderungen vollzogen sich sehr viel schneller als von Darwin angenommen: Sie gingen noch während des Lebens eines Individuums vor sich. Sie ergaben sich durch unerwartete Kontakte und durch mimetische Prozesse, die nicht darauf warteten, dass die stille und gemächliche Arbeit der Reproduktionszyklen die besten Merkmale einer Spezies auswählte." von Natur im Amazonas erscheint vor diesem Hintergrund als Produkt einer Gegenwart, die der Fiktion einer binären Aufteilung von Natur und Kultur und, damit verbunden, der Illusion von Naturkontrolle erlegen ist. Auf diese Fiktion und ihre Ursprünge weist Oloixaracs Roman hin, indem er, als sich der (europäische) Naturschutzgedanke zu formieren beginnt, eine parallele Naturgeschichtsschreibung beginnen lässt. Mit dem spekulativen Botaniker Niklas eröffnet er eine Gegenerzählung, die sich dem Hybriden, in der Figur der Ratte Hoichi, überantwortet und Niklas schließlich in der Dichte des Waldes verschwinden lässt.

\subsection{Perspektivverschiebungen: Multinaturalismus}

Die Figur der Dunkelwolken, der Verkehrung des Informationsgehalts von Positiv- und Negativformen, bestimmt den ganzen Roman und alle drei Erzählebenen. Das Vorbild, das astronomische System der Inka, transformiert die Dunkelheit, wenn man sie lesen kann, in Information, das Licht dagegen in "Grundrauschen", "ruido" (Oloixarac 2015, 195; 2016, 152). Die Adaption der indigenen Kosmologie liefert dem Roman einerseits die Möglichkeit, alternative Wissenschaftssysteme denkbar werden zu lassen (wie Niklas' antidarwinistische Evolutionstheorie). Unter den "Strahlen dunkler Materie" (Oloixarac 2015, 98; 2016, 128) bietet sie zudem die Grundlage für Kritik und Alternativen zur europäischen, lichtzentrierten, aufklärerischen Vernunft. Oloixaracs Roman zeichnet das Narrativ des Anthropozäns selbst als ein apokalyptisches, katastrophisches aus. Mit dem Beginn des Romans im Todesjahr Darwins bietet er eine phantastische Alternativgeschichte an und beschreibt zugleich den Umschlagspunkt, auf dem das hoffnungsvoll fortschrittsorientierte Zeitalter des Evolutionismus und der Höherentwicklung sich der ökologischen Konsequenzen dieser Fortschrittskategorien bewusst wird.

Die Lesbarkeit der Dunkelheit bzw. die Verkehrung von Figur und Grund in den constelaciones oscuras wird nicht nur für Niklas, sondern auch für Cassio handlungsleitend: Das Unternehmen, für das er - zu einem berüchtigten Hackergenie herangewachsen - schließlich arbeitet, heißt STROMATOLITHON. In Verbindung mit 
dem Projekt zur Regionalen Reorganisation der genetischen Daten Lateinamerikas (eine ironische Wendung des "Prozesses der Nationalen Reorganisation", dem Begriff, mit dem die argentinische Militärdiktatur selbst den "schmutzigen Krieg" gegen ihre Gegner beschrieb) verknüpft es eine DNA-Datenbank mit den digitalen Überwachungsdaten und Bewegungsprofilen von Handys, Kreditkarten und Überwachungskameras ganz Lateinamerikas. Zusammen mit der staatlichen Gendatenbank, in der jedes Neugeborene seit 2012 erfasst wird, bildet STROMATOLITHON ein perfektes Überwachungssystem. Zugleich dient es der Verteidigung der regionalen genetischen Daten, als „último bastión del Estado-nación en el siglo XXI" (Oloixarac 2015, 165).23 Die verschiedenen Zentren für technische DNA-Reproduktion und Datenanalyse befinden sich im Übrigen mitten im amazonischen Urwald.

Die so erzeugten Data-Doubles lassen sich ohne das Wissen des jeweiligen Individuums jederzeit und zu allem befragen. Cassio - der daran arbeitet, eine Technologie zu entwickeln, die eine solche Masse an Daten prozessieren kann - widmet sich dabei der "Lesbarkeit der dunklen Konstellationen der Welt", all jene Punkte in der Welt also, die noch nicht datentechnisch verarbeitet wurden: „ahora que la oscuridad era legible, se volvía lumínica. Pronto no habría donde esconderse" (Oloixarac 2015, 197). ${ }^{24}$ Dabei ist es nicht Cassio, sondern es sind die Algorithmen von STROMATOLITHON, die radikale Sichtbarkeit produzieren, garantieren und verarbeiten: Es ist das "Gehirn-Auge", "el ojo-cerebro" (Oloixarac 2015, 227; 2016, 181), seine Algorithmen sind darauf trainiert, das Auge ausfindig zu machen. Sie sehen Augen, und sie sind selbst megalomanes Auge, das nur die Augen der Menschen selbst nicht mehr wahrzunehmen in der Lage sind. Es ist der „aparato sensorial de la biométrica desaforada" (Oloixarac 2015, 168), ${ }^{25}$ der Sinnesapparat einer maßlosen Biometrie.

23 Dt.: Die "letzte Bastion des Nationalstaats im 21. Jahrhundert." Oloixarac 2016, 131.

24 Dt.: „Nun, da man die Dunkelheit lesen konnte, wurde sie selbst zur Lichtquelle. Bald würde es keinen Ort mehr geben, an dem man sich verstecken könnte." Oloixarac 2016, 153.

25 Dt.: „[Der] Wahrnehmungsapparat, der die maßlose und teils gesetzwidrige biometrische Datenverarbeitung ermöglichte." Oloixarac 2016, 133.
Cassios Begegnung mit diesem nichtmenschlichen Wahrnehmungshybriden aus digitalen und genetischen Daten geht eine ähnliche Begegnung seines Doppelgängers Niklas voraus, des spekulativen Botanikers und seines Narrativs vom Anthropozäns. Als dieser auf den amazonischen Mutanten Hoichi trifft, lehrt inn die hybride Ratte: "Hay tantas cosas que nos miran y no vemos" (Oloixarac 2015, 213), "So viele Dinge blicken uns an, und wir sehen sie nicht" (Oloixarac 2016, 168). Mit inm blickt nun das sonst Übersehene zurück: "Todo puede convertirse en otra cosa. Es la enseñanza de la selva, mi amigo" (Oloixarac 2015, 216). ${ }^{26}$ Die Ratte als verkörperte Perspektivverschiebung wird nun auf der Erzählebene Cassios nicht nur von STROMATOLITHON gedoppelt. Cassio ersinnt schließlich, als er sein Gewissen entdeckt, gemeinsam mit der Biologin Piera einen Hybrid aus biologischen und Computerviren, den er sich injizieren lässt, um mit ihm das ganze Datensystem zu infizieren und weltweit zu verteilen: Seine letzte große Tat als Hacker versucht, die Sichtbarkeiten vor der Kommodifizierung zu schützen und stattdessen zu demokratisieren: Das Übersehene sieht auch hier zurück.

Aktuelle Amazonasethnographien gehen davon aus, dass nahezu alle indigenen Völker des Amazonasgebiets Tiere und viele andere nichtmenschliche Wesen als beseelte, sinnerzeugende, intentionale Subjekte wahrnehmen. Sie denken "perspektivisch", in dem sie in der Lage sind, auch nichtmenschlichen Wesen eine Perspektive und ein Selbst zuzuerkennen. Diese Denkform resultiert wiederum, wie der Anthropologe Eduardo Kohn in seinem Buch über die Runa aus Ávila und den amazonischen Perspektivismus argumentiert, aus einer besonders dichten Ökologie verschiedener Subjekte - aus einem relationalen Netz, das weit jenseits des Menschen gespannt ist: "It's a response to the challenges of getting by in an ecology of selves whose relational webs extend well beyond the human, and it emerges from everday interactions with forest beings" (Kohn 2013, 96). Sein brasilianischer Kollege Eduardo Viveiros de Castro versucht den Unterschied zwischen westlichen und amazonischen Denksystemen „in Perspektive zu setzen"

26 Dt.: „alles kann sich jederzeit in etwas anderes verwandeln. Das ist es, was der Urwald uns lehrt, mein Freund." Oloixarac 2016, 171. 
(Viveiros de Castro 2016, 260), indem er sie über die Begriffe von Multinaturalismus und Multikulturalismus beschreibt: ${ }^{27}$ Während der moderne europäische Multikulturalismus sich auf der Überzeugung gründe, dass eine Einheit der Natur, also eine "Allgemeinheit der Körper und der Substanz" von einer Vielzahl möglicher, verschiedener Kulturen begleitet werde, basiere der Multinaturalismus der amazonischen Indigenen auf einer Einheit des Geistes und einer Vielheit der Körper (Viveiros de Castro 2016, 260). Der (unser westlicher) Multikulturalismus geht davon aus, es gebe eine allgemeine objektive Natur der Körper, die sich mit Gesetzen beschreiben lasse, die für alle Körper gelte - die Gesetze der Kultur aber seien viele, variabel, bestimmt von einer Vielzahl subjektiver Signifikate. Der Multinaturalismus ermöglicht dagegen Prozesse der körperlichen Erscheinungswechsel, "ein Prozess der in der ,höchst wandelbaren Welt' [...] der amazonischen Kulturen allgegenwärtig ist" (Viveiros de Castro 2016, 262), weil er Körper als "aktive Affektivität" bestimmt, die sich über ihren Standpunkt definieren, der wiederum die Voraussetzung des Subjekts ist, nicht anders herum. Viveiros de Castro grenzt dieses System klar ab von der Vorstellung eines kulturellen Relativismus. Der Multinaturalismus habe eine einzige "Kultur" und viele "Naturen", "eine beständige Epistemologie und eine variable Ontologie" (Viveiros de Castro, 288), setze also nicht variable Vorstellungen, sondern multiple Perspektiven voraus, die sich nicht aus den jeweiligen geistigen Zuständen, sondern aus je verschiedenen Körpern ergeben würden. Während für das europäische Denken die Seele der Ort ist, an dem Unterscheidungen getroffen werden (haben Tiere eine Seele?), sei es für die Indigenen des Amazonas der nicht als materielle Substanz gedachte Körper (hat der Körper eine Perspektive oder nicht?). Da die Seele allgemein ist, kann sie die Körper wechseln, die Perspektiven vertauschen.

Der Amazonas ist, folgt man Viveiros de Castro, nicht deswegen so faszinierend für den Westen, weil wir hier lernen, mehr kulturelle Relativität wahrzunehmen, als wir es ohnehin schon

27 Dabei schließt er an den Versuch des Lévi-StraussSchülers Philippe Descola an, "unsere" westlich geprägten Denksysteme „als Sonderfall in einer allgemeinen Grammatik der Kosmologien" zu verstehen vgl. Descola 2011, 142. tun. Im Gegenteil: Er ist es, weil wir dort natürlichen Perspektivismus erlernen können. Hoichi, STROMATOLITHON ${ }^{28}$ und Cassios Virus sind in diesem Sinne nichtmenschliche Akteure, die in Oloixaracs eine eigene Perspektive erhalten, ein Standpunkt und Wahrnehmungsfähigkeit haben, die grundlegend verschieden von unserer ist, weil sie an andere Körper (Tierkörper, Datenträger und deren "Gehirn-Augen") geknüpft sind. Innerhalb des Romans werden Menschen in Code übersetzbar, ihr Körper wechselt vom Humanen zum Datenträger, seine DNA wie auch seine Perspektive aber bleiben erhalten, auch wenn der Körper wechselt. Die Constelaciones oscuras ermöglichen eine weitreichendere Perspektivverschiebung als eine bloße Verkehrung des Informationsgehalts zwischen hell und dunkel: Ihre Orientierung an einem amazonisch-multinaturalistischem Modell ermöglicht es, Wahrnehmung als etwas zu verstehen, das, weil es von Körpern (und nicht mehr von Geistern) ausgeht, vom Menschen lösbar und multiplizierbar ist. Die Lektüre des Romans wird dann zur Simulation amazonischer Dichte, die es erlaubt, sich lesend in multinaturalistischen Wahrnehmungsformen zu üben.

\subsection{Rausch statt Rauschen: Prothetische Wahrnehmung}

Folgt man dem multinaturalistischen Ansatz, bedeutet das auch eine enorme Komplizierung der Wahrnehmungssituationen: "So viele Dinge blicken uns an, und wir sehen sie nicht." Welche Wahrnehmungsweisen bräuchte es, um derart multiplizierte Wahrnehmungsakte erfassen zu können? Und welche Vermittlungsformen wären nötig, um mit den verschiedenen Akteuren zu kommunizieren?

Eduardo Kohn antwortet auf diese Fragen mit einem "pansemiotischen" Ansatz, der auf der Grundlage der Zeichentheorie von Peirce davon ausgeht, dass Tiere und Pflanzen zwar nicht mit-

28 Vor allem in Verbindung mit den technisch-menschlichen Nasen, den "Bionose"-Apparaturen, die analog zur Überwachungskamera die Luft auf DNA-Partikeln scannen: Eine genetische Überwachungstechnologie, mit der der Roman zusammen mit flächendeckender visueller Erfassung eine Dystopie radikaler Datenerfassung erschafft, mit der Bezeichnung als Riechorgan aber ebenfalls auf der Ebene sinnlicher Wahrnehmung angesiedelt ist. 
tels symbolischer Zeichen kommunizieren, allerdings von indexikalischen und ikonischen Zeichen Gebrauch machen. Mit dieser Fokussierung auf andere Repräsentationsweisen von Welt, die weder dem Menschen entstammen noch auf inn beschränkt sind, öffne sich, so Kohn, auch eine neue Perspektive auf menschliche semiotische Prozesse: Indem man andere Kategorien auf den Menschen anwende als seine eigenen - wie Sprache, Kultur und Geschichte -, erschlössen sich neue Dimensionen für die Anthropologie, eine "Anthropologie jenseits des Menschen". Diese bricht zudem mit einer bestimmten Auffassung von "natürlichen" und "künstlichen" Weisen des Weltbezugs: Kohn zufolge konstruiert jedes Lebewesen quasi unnatürliche, im Sinne von künstliche, auf Zeichengebrauch basierende Welten. ${ }^{29}$ Das perspektivische Denken der Runa aus Ávila erlaube es ihnen nun, jede Lebensform als etwas mit eigener Perspektive auf die Welt (und damit auch auf den Menschen) zu begreifen. Die so entstehenden vielfältigen Blickrichtungen erzeugten ein dichtes Netz, eine "ecology of selves", die Kohn zum Anlass nimmt, Leben selbst als grundsätzlich semiotisch zu definieren. ${ }^{30}$

Seine Analyse des relativ gesehen menschenleeren amazonischen "web of living thoughts" (Kohn 2013, 78) trägt dazu bei, konkrete Praktiken zu benennen, mithilfe derer es möglich werden kann, von der anderen Seite her auf den Menschen zu blicken, auf der Basis dieser Vielzahl an Perspektiven das Menschliche zu defami-

29 Kohns Ansatz nichtmenschliche Arten von Repräsentation zu fokussieren, ist allerdings im Gegensatz zum Verantwortungsdiskurs, der in den Traurigen Tropen vorherrscht, weniger als ethisches Projekt angelegt, denn als ein epistemologisches. Sein Blick auf die Runa im Amazonasgebiet, die zahlreiche nichtmenschliche Akteure als beseelte, sinnerzeugende und intentionale Subjekte behandeln, dient nicht etwa einer exotisierenden Zuschreibung, sondern einer Kritik westlicher Denkweisen, ohne daraus konkrete (verantwortliche) Handlungsweisen gegenüber dem untersuchten Gegenstand abzuleiten.

30 Unter dem Titel "Provincializing language" will er also zeigen, dass Zeichengebrauch nicht auf die dem Menschen vorbehaltene symbolische Sprache beschränkt ist. Jedes Lebewesen, ob Pflanze oder Tier, mache von indexikalischen oder ikonischen Repräsentationen Gebrauch und müsse damit als ein denkendes Ich verstanden werden. Das denkende Ich wiederum entstehe, so Kohn, aus einer Dynamik von Bezugnahmen auf Abwesenheit, Zukunft und Zielgerichtetheit, Wachstum bzw. Lernfähigkeit sowie der Fähigkeit zum Irrtum. liarisieren und seine dezentrale Position innerhalb eines vielfältigen Netzwerkes von verschiedenen Repräsentationen überhaupt erst verstehbar zu machen. Er liefert also von ethnologischer Seite eine weitere amazonische Lektion in Perspektivverschiebungen, die sich als eng verwandt mit dem literarischen Unternehmen Oloixaracs ausweist, und unternimmt dabei statt (post)kolonialer Zuschreibungen eine Kritik an westlichen Repräsentationsweisen.

In ganz ähnlicher Hinsicht geht der Ethnologe Viveiros de Castro davon aus, dass eine spezifische Vermittlungsfigur - der Schamane als "Diplomat" zwischen der Welt der Menschen und der Welt der Geister - Teil vieler Denksysteme des indigenen Amazonas sei. Geister im Amazonas seien weniger personifizierte Imaginationen als "ontologischer Modus vom Typ der, intensiven virtuellen Vielfalt"' (Viveiros de Castro 2007, 155). Die Schamanen der Yanomami seien in der Lage, z.B. die Xapiripë-Geister wahrzunehmen, wenn sie das Puder eines bestimmten Baumes einatmeten (Viveiros de Castro 2007, 153). Denn die Geister ernährten sich von diesem Baum: Und erst, wenn der Schamane die gleiche Nahrung aufnehme wie sie, könne er sie auch sehen. Im besonderen Fall der Xapiripë-Geister bilden diese die „Bilder der Tiere des Waldes" (Viveiros de Castro 2007, 154), jedes Tier hat sein Bild, sie sind das eigentliche Zentrum des Waldes. Ein Schamane ist also "ein Freund des Bildes" - wobei hier ein grundsätzlich anderer Bildbegriff zugrunde gelegt werden muss: Die Geister-Bilder sind nicht-ikonisch und nicht-sichtbar. Sie bestehen vielmehr in indexikalischen Verweisen auf einen mentalen Status, auf die charakteristischen Affekte einer bestimmten Tierart, dessen Bilder sie sind: Bilder konstituieren sich dann über affektive Verweisungszusammenhänge statt über ikonische Ähnlichkeit zu einem Referenten. Und es sind Bilder von anderer Sichtbarkeit: Sie sind einem besonderen Modus der Wahrnehmung zugänglich, zugleich sind es Bilder, die uns sehen, bevor wir sie sehen können, die uns verstehen, bevor wir sie verstehen können. Um diese Form der Wahrnehmung zu beschreiben, verfällt Viveiros de Castro schließlich auf Frequenz-Metaphern: Es gebe eine "human mode" und ein "animic field", auf denen die Geister als Frequenzen unter den Wahrnehmungsgrenzen des menschlichen Auges lägen. Die Schamanen könnten dann mithilfe des hallu- 
zinogenen Baumpuders zu Empfängern werden: Entscheidend sei, dass sie auf den gleichen Frequenzen empfangen können wie die Geisterbilder. Schamanen sehen die Geister nicht, sondern sie sehen wie die Geister: Durch die temporäre Veränderung ihres ontologischen Status können die Schamanen auch an anderen Wahrnehmung Anteil haben (Viveiros de Castro 2007, 159-162).

Um das dichte Netz der Perspektiven überhaupt als Möglichkeit zu erfassen, ist es also nötig, zunächst eine Vielheit von Körpern und daran geknüpfte verschiedene Blicke auf die Umwelt zu unterstellen. Sei es durch Provinzialisierung des Zeichenbegriffs, wodurch das Symbolische als menschlicher Sonderfall ausgezeichnet wird, sei es durch die Idee einer schamanistischen Technologie, deren Basisinstrument und visuelle Prothese in halluzinogenen Stoffen besteht: In den Wahrnehmungstechniken des Amazonas spielen Prothesen eine entscheidende Rolle, um das Rauschen der dichten, "sylvan" "ecology of selves" erfassen zu können.

Auch der Hacker Cassio in Oloixaracs Roman lässt sich über die Verknüpfung von Geisterund digitalen Bildern als eine Schamanenfigur beschreiben: Geisterbild und Code, als zwei Formen alternativer Sichtbarkeit, bilden Strukturen in der Sphäre des Virtuellen. ${ }^{31}$ Ähnlich wie die Schamanen bei Viveiros de Castro ist seine vermittelnde Arbeit zwischen Menschen und Daten ein kosmischer Akt der Diplomatie, eine gesellschaftlich entscheidende Moderation zwischen zwei ontologischen Sphären mit jeweils unterschiedlichen Perspektiven auf die Welt. Cassio gelingt dies mittels der von der Biologin Piera konzipierten technischen Prothese, einem selbstentwickelten Virus, einer Mischung aus genetischen und digitalen Daten. Diesen lässt er sich von ihr injizieren und wird dadurch gerade kein "super-individual", sondern ein "super-divided being" (Viveiros de Castro 2007, 156), insofern er

31 Cassio referiert in Oloixaracs Roman immer wieder ironisch auf den Kleinen Prinzen: „Das Wesentliche ist für die Augen unsichtbar (weil wir eine Vulnerabilität in der Software nur finden können, wenn wir uns in sie vertiefen)" Oloixarac 2016, 53; "lo esencial es invisible a los ojos (porque sólo podemos encontrar una vulnerabilidad en el software si nos sumergimos en él)" Oloixarac 2015, 69 [Herv.i.O.]. Cassio benötigt folglich andere Sinne, um den Code hinter der Sichtbarkeit zu erfassen. über körperliche Transformation an verschiedenen Modi der Wahrnehmung teilhaben kann.

Aus Oloixaracs Roman lässt sich folgern: Es braucht eine neue Sinneslehre für den Datenkontinent. „El enorme, nuevo continente de datos representaba el nuevo mundo por descubrir: había que diseñar los sentidos, el tacto, la vista, que pudieran percibir ese laberinto" (Oloixarac 2015, 166). ${ }^{32}$ Statt aber angesichts des Amazonas einen Abgesang auf eine ursprüngliche Naturform der Sinne anzustimmen, lässt sich - besonders dann, wenn man den Roman vor dem Hintergrund des amazonischen Perspektivsmus liest - nachweisen: Es sind nicht (allein) die digitalen Datenkontinente, die uns zu neuen Wahrnehmungsweisen zwingen: Die Anerkennung anderer Akteure als Wahrnehmende - seien es Algorithmen, Hunde oder Geisterbilder - erfordert prothetische Wahrnehmungstechnologien:

The glittering webs of the new communications, trans-
portation, and genetic technologies are not simply cast
over us by greedy corporations forced to sell what they
overproduce. On the contrary, these new human-fos-
tered technologies are in a direct line with the old.
All arose from precedents - prehuman precedents -
in an evolutionary and ecological context. Technology
is a part of the human survival strategy [...] it has
extended our ability to sense and manipulate the envi-
ronment that supports us. It has been with us from the
time long before we were human beings[.] (Margulis/
Sagan 2007, 76-88)

Die (philosophisch) anthropologische Erkenntnis, das Wahrnehmung immer schon prothetisch funktioniert hat, fällt bei Oloixarac dagegen zusammen mit dem Hinweis darauf, dass der menschliche Blick längst nicht mehr die einzige oder dominante Perspektive auf Welt ist und ohnehin nie war.

Niklas Bruun, der spekulative Botaniker, beschreibt am Ende des 19. Jahrhunderts in "la penumbra de los documentos" (Oloixarac 2015, 18; 2016, 11), im "Halbdunkel der Dokumente", und ohne es selbst zu wissen, eine geheime Pflanze, die Crissia pallida: spinnenartig, golden leuch-

32 Dt.: „Der riesige Kontinent der Daten war die Neue Welt, die es jetzt zu entdecken galt: Es mussten die entsprechenden Instrumente ausgebildet werden, ein Tastsinn und ein Sehsinn, die fähig waren, dieses Labyrinth zu erobern." Oloixarac 2016, 132.

33 Dank an Hannes Bergthaller für diesen Hinweis. 
tend, von betäubender wie auch halluzinogener Wirkung, an der Grenze des organischen Lebens. Aus diesem Grenzbereich zwischen Pflanze und Tier, Leben und Tod greife sie ihre Feinde an. Niklas Schriften, von "seherischer Sprache", "el tono absoluto, que no resuena en ninguna garganta" (Oloixarac 2015, 136; 2016, 105), bald wissenschaftlich, bald imaginär, erwähnen Pflanzen, die es außerhalb seiner Texte wohl nie gegeben hat. Seine halluzinierende Prosa befasst sich mit Hybriden, mit manipulativen Parasiten und Symbiosen: Der Schluss liegt nahe, dass sie unter dem Einfluss der geheimen Pflanze verfasst wurden. Wie ein Schamane atmet Niklas pflanzliche Dämpfe ein und ist dadurch in der Lage, zwischen den Wissensordnungen zu vermitteln: Die delirierende Einbildungskraft angesichts der amazonischen Dichte führte für Lévi-Strauss nur zur eklektischen Lyrik, Niklas und Cassio aber sind einem Code auf der Spur, um das Rauschen in Information zu übersetzen.

Der Amazonas als Heimat der "chronisch Heimatlosen" hat nun nicht mehr primär die Funktion, zur Entwurzelung der Wahrnehmung zu führen, indem er alle erlernten westlichen Wahrnehmungskonventionen an ihre Grenzen bringt und sich erst nach dieser Form der Entwurzelungserfahrung ein verfremdender Blick auf das Eigene werfen lässt. Die Überlegungen, die sich aus Roman und aktuellen ethnologischen Ansätze zum amazonischen "sylvan thinking" ableiten lassen, legen nun einen anderen Schluss nahe: Statt einer Wahrnehmungshygiene, einer Entwurzelung oder eine Renaturalisierung von Wahrnehmungsformen scheint das eigentliche Paradigma einer Prothetik der Wahrnehmung aus dem Amazonasgebiet zu stammen.

Die indigenen Denksysteme im Amazonasgebiet greifen auf eine deutlich längere Tradition und Übung in Perspektivverschiebungen und selbstreflexiven Techniken der Defamiliarisierung zurück, im Denken in Netzwerken und im Versuch, anzuerkennen, wie viele Dinge uns anblicken. Statt amazonischer Wahrnehmungshygiene treffen zeitgenössische Anthropolog*innen hier auf einen eingeübten Umgang in medialer Wahrnehmung, der den Übergang von natürlicher und prothetischer nicht als Dekadenzgeschichte erzählt. Die Constelaciones oscuras setzen dort an und führen die amazonischen Perspektivverschiebungen zurück in die Vergangenheit. Vom
Totenbett Darwins aus erzählt der Roman eine Alternativgeschichte zum evolutionären Paradigma und setzt gegen die Idee von Fortschrittsund Artentwicklung die Vorstellung symbiotischer Beziehungen und Tauschgeschäfte quer zu den Artengrenzen, orientiert an den Denksystemen amazonischer Indigener. Zugleich imaginiert der Roman aber auch den Preis für die Marginalisierung der menschlichen Perspektive: Denn zumindest die Pläne der hybriden Ratte Hoichi zielen auf Versklavung des Menschen, und sowohl Niklas' als auch Cassios Existenz als menschliche Individuen scheinen am Ende des Textes in Auflösung begriffen.

\section{Heimat des Verschwindens}

In Ethnologie, Kunsttheorie und Literatur des 20. Jahrhunderts ähneln sich die Versuche, angesichts des Amazonaswaldes neue Wahrnehmungsweisen einzuüben. Um soziale Beziehungen, Zeichengebrauch und Sprache der eigenen Gesellschaft genauer wahrnehmen zu können, bedürfe es des Blicks auf das radikal Fremde, das den Status eines bedrohten, aber gerade noch vorhandenen ,Natürlichen' trage. Erst in diesem Spiegel könne Anthropologie oder Kunst heimisch in der eigenen Sprache werden. Zu Beginn des 21. Jahrhunderts und mit der plötzlich dringlich gewordenen Reflexion jenes ,Menschenzeitalters' wandelt sich auch die Funktion der traditionsreichen epistemologischen Reise durch die amazonische Dichte: Erst wenn sich die Vorstellung einer Hygiene der Wahrnehmung in ihr Gegenteil wendet, werden dort die Verstrickungen sichtbar: Es geht dann nicht mehr um die mahnende Zeugenschaft einer zerstörten, stummen, passiven Natur. Die Idee von Naturschutz kann dann allerdings ebenso wenig mit einer "Politik [...] erhabener Indifferenz" (Haraway 2018 , 13) ad acta gelegt werden. ${ }^{34}$ Stattdessen offenbart das Unternehmen des Perspektivismus seine radikale Ambivalenz: Einerseits scheinen in

$34 \mathrm{Vgl}$. für eine solche Position der erhabenen Indifferenz etwa die scheinbare Demontage des Naturschutz-Konzepts als radikal kulturalistisches bei Rolf Peter Sieferle: "Was geschützt werden muß, ist ja gerade nicht mehr natürlich vorhanden, es existiert nicht mehr aus eigenem Vermögen, sondern ist letztlich dem Willen des Schützenden unterstellt" Sieferle 1997, 218. 
den Constelaciones oscuras die eigensinnigen Verwandtschaften auf, die es ermöglichen sollen, "die Fesseln des Anthropozäns und des Kapitalozäns zu zerschneiden" (Haraway 2018, 13). Andererseits geht der Roman zwischen Genetik, Virologie, Kryptologie und Ökologie mit seiner in die Zukunft blickenden Science-Fiction die Netzwerke jenseits des Menschen so weit, dass der Mensch droht, selbst übersehen zu werden: Das Ende des Textes legt die Verwandlung von Niklas in eine Pflanze nahe: Er verschwindet im Urwald, auf der Suche nach "hybriden Wesen" (Oloixarac 2016, 179; 2015, 224) und wird nicht mehr gesehen. Cassio, dessen Hackerleben sich ohnehin per se im Verborgenen abspielt, der es als Kind der 1980 er Jahre bis 2024 geschafft haben wird, dass keine einzige Fotografie von ihm erhalten ist, ${ }^{35}$ übt sich in der "Kunst des Verschwindens", "el arte de desaparecer" (Oloixarac 2016, 185; 2015, 232), bis er sich in den "Wälder[n] der Anonymität" (Oloixarac 2016, 184) ${ }^{36}$ verliert. Während Niklas nach dem Verfassen delirierender letzter Texte sich schließlich ergibt und zur Orchidee zu werden scheint oder aber als bloßer Kontemplateur im Wald verschwindet, löst die Transformation des Hackers Cassio auf zweiter und dritter Ebene wiederum das ein, was Hoichi forderte: Der Preis der Perspektivverschiebungen hin zu den intimen Verbindungen zwischen Mensch, Tier, Pflanze und digitalem Code ist der Verlust des ,natürlichen' Menschen. Die neue Welt, der neue Kontinent, ist virtueller Natur, und für die Wahrnehmungsweisen des Virtuellen bildet der amazonische, sich in permanenter Verwandlung befindliche Ort des Urwalds die ideale Matrix.

Laut dem eingangs zitierten Davi Kopenawa, Wortführer der Yanomami, Schamane und Denker, ist das weiße Äquivalent zu den Tiergeistern, die Halluzination der Weißen also, die gelehrte Vernunft. Und daher, schließt Viveiros de Castro daraus, ist Schreiben ihr Schamanismus: "To be able to see them [the xapiripë] you must inhale

35 Außer einer einzigen, im Buch abgedruckten, fingierten Fotografie aus dem Labor von STROMATOLITHON, die Cassio und Max Lambard zeigt. (sp.: 25f; dt.: 17) Es wäre lohnenswert, genauer auf den Abbildungsgebrauch in den Constelaciones oscuras einzugehen und den Status der Illustrationen und der fingierten Fotografien mit den virtuellen Tierbildern der Yanomami in Beziehung zu setzen.

36 Sp.: „antes de perderse en la selva anónima" Oloixarac 2015, 231. the powder of the yãkõanahi tree many, many times. It takes as much time as Whites take to learn the design of their words" (Viveiros de Castro 2007, 156). Der Roman wird zum schamanistischen Akt der Diplomatie, um mit den weißen Halluzinationen in Kontakt zu treten. So bleibt der Amazonaswald zwar der überdeterminierte Referenzpunkt für die wechselnden westlichen Wahrnehmungsparadigmen diesseits und jenseits von Natur und Kultur. Der schamanistischen Leistung des literarischen Textes aber kann es gelingen, zwischen den verschiedenen Wissensbeständen, die der Sphäre des Virtuellen angehören und immer auch Ergebnis verschiedener Projektionen sind, und ihren jeweiligen Standpunkten zu vermitteln, um Perspektivverschiebungen einzuüben und dabei zugleich immer wieder die eigene Imaginationsleistung zu reflektieren.

\section{Literaturverzeichnis}

Benett, Jane (2017): Bilder von Odradek und die Ränder der Wahrnehmung. In: Renn, Jürgen/Scherer, Bernd (Hgg.): Das Anthropozän. Zum Stand der Dinge. Berlin: Matthes \& Seitz, S. 47-66.

Descola, Philippe (2014): All too human (still). A comment on Eduardo Kohn's How forests think. In: HAU: Journal of Ethnographic Theory 4, H. 2, S. 267-273.

Descola, Philippe (2011): Jenseits von Natur und Kultur. Hg. von Michael Kauppert. Übers. von Eva Moldenhauer. Berlin: Suhrkamp.

Falb, Daniel (2015): Anthropozän. Dichtung in der Gegenwartsgeologie. Hg. von Asmus Trautsch. Berlin: Verlagshaus Berlin (= Edition Poeticon 09).

Haraway, Donna (2018): Unruhig bleiben. Die Verwandtschaft der Arten im Chthuluzän. Übers. von Karin Harrasser. Frankfurt am Main/New York: Campus Verlag.

Hermannstädter, Anita/Ethnologisches Museum Berlin/ Brasilianisches Kulturinstitut in Berlin (Hg.) (2002): Deutsche am Amazonas. Forscher oder Abenteurer? Expeditionen in Brasilien 1800 bis 1914. Berlin/ Münster: Lit Verlag.

Heyne, Elisabeth (2019): Wie sammelt man das Imaginäre? Von der Leuchtzirpe. In: Avenue. Das Magazin für Wissenskultur 7, S. 42-47 und https:// avenue.jetzt/sammeln/wie-sammelt-man-dasimaginaere-von-der-leuchtzirpe/.

Heyne, Elisabeth (2020): Wissenschaften vom Imaginären. Sammeln, Sehen, Lesen und Experimentieren bei Roger Caillois und Elias Canetti. Berlin: De Gruyter.

Kohn, Eduardo (2013): How forests think. Toward an anthropology beyond the human. Berkeley: University of California Press. 
Latour, Bruno (2018): Wir sind alle wie Trump. Der Soziologe Bruno Latour über Klimawandel, Heimat und Globalisierung - und die Notwendigkeit einer Neuorientierung jenseits der traditionellen politischen Kategorien. In: Frankfurter Allgemeine Sonntagszeitung vom 13.05.2018.

Lévi-Strauss, Claude (1981): Traurige Tropen [1955]. Übers. von Eva Moldenhauer. Frankfurt am Main: Suhrkamp.

Margulis, Lynn/Sagan, Dorion (2007): Welcome to the machine. In: Dies.: Dazzle gradually. Reflections on the nature of nature. White River Junction: Chelsea Green Pub, S. 76-88.

Mollard, Claude/Lismonde, Pascale (2005): Frans Krajcberg, la traversée du feu: biographie. Paris: Isthme.

Morton, Timothy (2013): Hyperobjects. Philosophy and ecology after the end of the world. Minneapolis: University of Minnesota Press (= Posthumanities 27).

Oloixarac, Pola (2015): Las constelaciones oscuras. Buenos Aires: Literatura Random House.

Oloixarac, Pola (2016): Kryptozän. Übers. von Timo Berger. Berlin: Wagenbach.

Restany, Pierre (2005): Manifeste du naturalisme intégral [1978]. In: Mollard, Claude, Pascale Lismonde: Frans Krajcberg, la traversée du feu. Paris: Isthme, S. 229-232.

Rottenburg, Richard (2001): Marginalität und der Blick aus der Ferne In: Behrend, Heike (Hg.): Geist, Bild und Narr. Zu einer Ethnologie kultureller Konversion. Festschrift für Fritz Kramer. Berlin: Philo, S. 37-44.
Sieferle, Rolf Peter (1997): Rückblick auf die Natur. Eine Geschichte des Menschen und seiner Umwelt. München: Luchterhand.

Viveiros de Castro, Eduardo (2007): The Crystal Forest: Notes on the Ontology of Amazonian Spirits. In: Inner Asia 9 H. 2, Special Issue: Perspectivism, S. $153-172$.

Viveiros de Castro, Eduardo (2016): Die Unbeständigkeit der wilden Seele. Übers. von Oliver Precht. Wien/ Berlin: Verlag Turia + Kant (= Neue Subjektile).

\section{Filmverzeichnis}

Herzog, Werner (1982): Fitzcarraldo [DVD] BRD.

\section{Abbildungsverzeichnis}

Abb. 1: The dark nebula LDN 483 (La Silla Observatory), Quelle: https://www.eso.org/public/images/ eso1501a/

Abb. 2: Claude Lévi-Strauss und Lucinda "Mr. Lévi-Strauss in Brazil in the 1930s", Quelle: https://www.nytimes.com/slideshow/2009/11/04/ arts/10091104_CLAUDE_SLIDESHOW_ index/s/20091105-strauss-slideshow_slide2.html

Abb. 3: Das botanisch-hybride Laboratorium inmitten des Urwalds, Abb. dt. Übers. Oloixarac 2016, Bildrechte: Jonathan Guggenberger 